\title{
Politics and political determinants of health policy and systems research funding in Latin America and the Caribbean
}

\section{Francisco Becerra-Posada ${ }^{a, b, m}$, Laura dos Santos Boeirac, Bárbara García-Godoy ${ }^{d}$, Elizabeth Lloyde, Héctor Xavier Martínez- Sánchez ${ }^{\dagger}$, Carolina O’Donnell ${ }^{\text {, }}$, Ulysses de Barros Panisset ${ }^{\mathrm{h}}$, Donald T Simeoni, Diana Salazar-Barragánj, Patricia Villa-Maldonadok and Mauricio Bustamante-Garcial}

a Universidad Autónoma de Nuevo León, Centro de Investigación y Desarrollo en Ciencias de la Salud, Monterrey, Mexico

b Florida International University Robert Stempel College of Public Health and Social Work, Global Health Consortium, Miami, Florida, US

c Instituto Veredas, Federal District, Brazil

a Universidad de Buenos Aires, Argentina

${ }^{\text {e }}$ Condell Consulting, Port of Spain, Trinidad and Tobago

† MCMX Consultants, Querétaro, Mexico

g Fundación H. A Barcelo, Instituto Universitario de Ciencias de la Salud, Buenos Aires, Argentina

n Universidade Federal de Minas Gerais, Belo Horizonte, Minas Gerais, Brazil

i The University of the West Indies, Caribbean Centre for Health Systems Research and Development, St Augustine, Trinidad and Tobago

i Independent health consultant, Bogota, Colombia

k Department of Women's Imaging, Clínica Montesur, Lima, Peru

I Global Health \& Education Management, Lima, Peru

${ }^{m}$ Corresponding author: fcobecerra@gmail.com

\section{Article history}

Publication date: 10 November 2021 Citation: Becerra-Posada F, dos Santos Boeira L, García-Godoy B, Lloyd E, Martínez-Sánchez HX, O'Donnell C, de Barros Panisset U, Simeon DT, Salazar-Barragán D, Villa-Maldonado $P$, Bustamante-Garcia M. Politics and political determinants of health policy and systems research funding in Latin America and the Caribbean. Public Health Res Pract. 2021;31(4):e3142120. https://doi. org/10.17061/phrp3142120

\section{Abstract}

Objectives and importance of study: The importance of health policy and systems research (HPSR) has been acknowledged since 2004 and was recognised by the United Nations World Health Assembly in 2005. However, many factors influence its development. This paper aims to analyse the impact of politics and political determinants on HPSR funding in selected countries of Latin America and the Caribbean.

Methods: Using a standardised protocol, we performed an analysis of available data and financing structures for health research and HPSR based on research in eight countries, including interviews with key stakeholders $(n=42)$.

Results: Dollar depreciation and gross national product growth in the region may play a role in how governments fund research. There have been shifts in the political spectrum in governments, which have affected research coordination and funding in positive and negative ways. HPSR funding in 


\section{Key points}

- The political environment has a direct impact on how health policy and systems research is financed in the Latin American and Caribbean region

- Health policy and systems research is seen as necessary, but it is underfunded

- There is a need for whole-of-government open-data policies to facilitate access to research financing data

- Countries need to increase their budgets and strengthen national health research systems to promote evidence-informed decisions for better health policies some countries was dependent on budget decisions and although some have improved funding, others have regressed by decreasing funding or have completely cancelled financing mechanisms. Caribbean countries rely mainly on institutional funding. HPSR is recognised as important but remains underfunded; stakeholders believed it should be used more in decision making.

Conclusion: Although HPSR is recognised as valuable for decision making and policy development, it does not have the financial support required to flourish in Latin America and the Carribean. Data on health research financing were not easy to access. There was little or no evidence of published reports or papers about research financing, health research funding, and HPSR funding in particular in the studied countries. Because of the fragility of health systems highlighted by the coronavirus disease 2019 (COVID-19) pandemic, HPSR should be of great relevance and value to both policy makers and funders.

\section{Introduction}

A landmark in health research, the Mexico Statement on Health Research, issued in 2004 at the closing of the World Health Organization (WHO) Ministerial Summit on Health Research states that "... crucial research aimed at strengthening public health and health systems has been neglected and under-funded. There should be a balanced and comprehensive research strategy that is inclusive of all relevant investigative approaches." The statement's call for action specifically highlighted the need for: "Funders of health research to support a substantive and sustainable program of health systems research aligned with priority country needs". ${ }^{1}$

Other international calls for support and funding of health policy and systems research (HPSR) urge countries to support and revamp their health systems using the best available evidence for their decisionmaking processes, from day-to-day decision making to policy design and implementation. ${ }^{2}$ Despite the establishment of $\mathrm{HPSR}^{3,4}$ as a recognised research discipline, these global appeals have not yet received adequate recognition and financial support.

The WHO Latin America and the Caribbean (LAC) region has enjoyed political stability, with democratically elected governments in most countries. The region has seen political shifts in some countries from conservative governments to progressive ones and back again. These changes have affected social policies, government structures and investment in science, innovation and technology. These shifts may have had an impact on HPSR financing, especially during the coronavirus disease 2019 (COVID-19) pandemic, as funds are increasingly redirected towards COVID-19 research while decreasing in other areas..$^{5,6}$

This paper is based on one of six reports commissioned by the WHO Alliance on Health Policy and Systems Research (Alliance) - one per WHO region - to explore the politics and financing of HPSR. It analyses the main findings of six LAC country report teams, examining trends in HPSR funding and the politics and political determinants of such funding in eight countries. ${ }^{7}$

\section{Methods}

This study is one of six multicentric projects supported by the Alliance. Based on the general guidelines and proposed survey formats agreed by all regional principal investigators ${ }^{8}$, the $L A C$ region principal investigator purposively selected countries that: have or had funding mechanisms for health research; had national government changes that occurred in the past 10 years; and had a reliable country-based researcher. Based on these criteria, Argentina, Brazil, Colombia, Mexico and Peru were selected from Latin America, and Barbados, Jamaica, and Trinidad and Tobago from the Caribbean.

Most of these eight countries have experienced some changes in the ideology of their governments or have faced political issues that may have affected investment in science and technology in the past decade. Argentina, Brazil, Colombia and Mexico have experienced a shift in government ideology and Peru has faced two presidential resignations, in 2018 and 2020 . The Caribbean was more stable politically; recent changes in governments have occurred via democratic electoral processes.

Research teams analysed published data on HPSR funding in each country, including reports about overall health research funding with a focus on HPSR, and data from interviews. Research in each country was carried out by one or two researchers who were responsible for following the accepted standardised protocol for all WHO regions.

All teams searched for national health research programs and/or priorities for the period 2010-2020 
as well as funding data from other official sources, publications and grey literature. Inflation rate analysis did not form part of this study.

Potential survey participants were identified first by researchers' brainstorming and then by snowball sampling after consultation with each country's stakeholders. Three groups of stakeholders were interviewed using a key informant interview guide, either by phone or video call. They included policy makers in health ministries, health policy and systems researchers, and other health researchers. All countries applied the same survey, which was translated into Spanish and Portuguese for the study. The survey investigated: the existence of a health research policy; individual perceptions about how budget allocations and funding for health research were conducted; opinions about whether funding for HPSR was adequate; and which departments, institutions or bodies decide on funding, as well as other issues.

As per the coordinating academic institution ethical requirements, we did not need to seek ethics approvals for this research. No consent forms were presented to interviewees since all the information was to be anonymised and they could decline participation. Invitation emails were sent inviting them to participate and describing the support by the Alliance. The surveys were carried out between September and October 2020.

Country reports were produced and integrated into a regional report, which was delivered to the Alliance; this paper summarises the findings.

\section{Results}

Argentina, Brazil, Colombia, Jamaica, Mexico and Peru are considered upper-middle income economies, and Barbados and Trinidad and Tobago are classified as highincome economies, according to the 2020 World Bank Country Classification. ${ }^{9}$

Brazil, Mexico, Argentina, Colombia and Peru are among the top 10 countries in the LAC that contribute to health research publications and the Caribbean countries are within the top 25, according to independent research group SCImago. ${ }^{10}$

Our survey was completed by 42 participants, 12 of whom were policy makers, 14 health policy and systems researchers and 16 health/biomedical researchers (Table 1).

In the studied countries, Ministries of Health $(\mathrm{MoH})$ exercised leadership and governance in health and some also coordinated health research. The science and technology (Sc\&T) sector had close ties with the $\mathrm{MoH}$ in most countries and was the main contributor to research funding. Each country had a different way of supporting its health research; a common denominator in Latin America was funding from Sc\&T councils or ministries, while for the Caribbean, funding was from $\mathrm{MoH}$ and universities.
Table 1. Number and type of key stakeholders from each country who participated in interviews

\begin{tabular}{lccc}
\hline Country & $\begin{array}{c}\text { Policy } \\
\text { makers }\end{array}$ & $\begin{array}{c}\text { Health policy } \\
\text { and systems } \\
\text { researchers }\end{array}$ & $\begin{array}{c}\text { Health/ } \\
\text { biomedical } \\
\text { researchers }\end{array}$ \\
\hline Argentina & 4 & 3 & 2 \\
Brazil & 1 & 4 & 3 \\
The Caribbean & 0 & 2 & 2 \\
(Jamaica, & & & \\
Trindad and & & 0 & 3 \\
Tobago, & & 5 & 1 \\
Barbados) & 0 & 0 & 5 \\
Colombia & 3 & $\mathbf{1 4}$ & $\mathbf{1 6}$ \\
Mexico & 4 & & \\
Peru & $\mathbf{1 2}$ & & \\
\hline TOTAL & & & \\
\hline
\end{tabular}

\section{Funding}

Overall research funding availability in the eight countries studied was dependent on national budget decisions, with elected bodies having the final say in annual budget allocations, despite existing legal frameworks or national development plans. This caused variations in budget allocations, triggering adjustments in the amounts disbursed annually for research. One mechanism that previously facilitated steady support and secure multiyear funding for projects was sectoral funds in Mexico (defunct since 2011), a research financing scheme that Colombia has now embraced. Sectoral funds involve a specific sector (i.e, health) and the national Sc\&T body investing research funds from their yearly budgets into a trust. The trust manages the available funds to ensure financial support of approved projects for their lifespan. ${ }^{11,12}$ This mechanism eliminates dependency on annual budget fluctuations.

The financial situation in the LAC region, which experienced declining gross domestic product (GDP) from 2010 to $2020^{13}$, along with exchange rate depreciation in most countries (Table 2), could have influenced budget appropriations for research financing.

The countries' overall investment in research and development $(R \& D)$ reported to the Ibero-American Network for Science and Technology Indicators (RICYT) showed a large difference between Brazil and the other countries in the study (Figure 1). There were declines in investment in most countries. ${ }^{14}$ Not all countries reported on a regular basis. 
Table 2. Exchange rates by country for US $\$ 1.00$ in 2010, 2015, 2020ª and GDP change

\begin{tabular}{|c|c|c|c|c|}
\hline Country & $\begin{array}{c}\text { Exchange rate } \\
2010\end{array}$ & $\begin{array}{c}\text { Exchange rate } \\
2015\end{array}$ & $\begin{array}{c}\text { Exchange rate } \\
2020\end{array}$ & $\begin{array}{c}\text { GDP change } \\
2010-2020(\%)\end{array}$ \\
\hline Argentinian peso & 3.90 & 9.23 & 78.22 & -20.0 \\
\hline Barbados dollar & 2.00 & 1.92 & 2.00 & -15.32 \\
\hline Brazilian real & 1.76 & 3.21 & 3.94 & -11.57 \\
\hline Colombian peso & 1542.85 & 2744.66 & 3714.70 & -11.33 \\
\hline Jamaican dollar & 87.23 & 116.80 & 141.70 & -8.85 \\
\hline Mexican peso & 12.39 & 17.09 & 21.70 & -13.34 \\
\hline Peruvian nuevo sol & 2.82 & 3.18 & 3.48 & -19.47 \\
\hline Trinidad and Tobago dollar & 5.14 & 6.35 & 6.76 & -11.15 \\
\hline
\end{tabular}

a Source: www.exchangerates.org.uk

Source: calculations using data from data.worldbank.org

Figure 1. Investment in research and development per country reported to Network for Science and Technology Indicators (RICYT), 2009-2019a

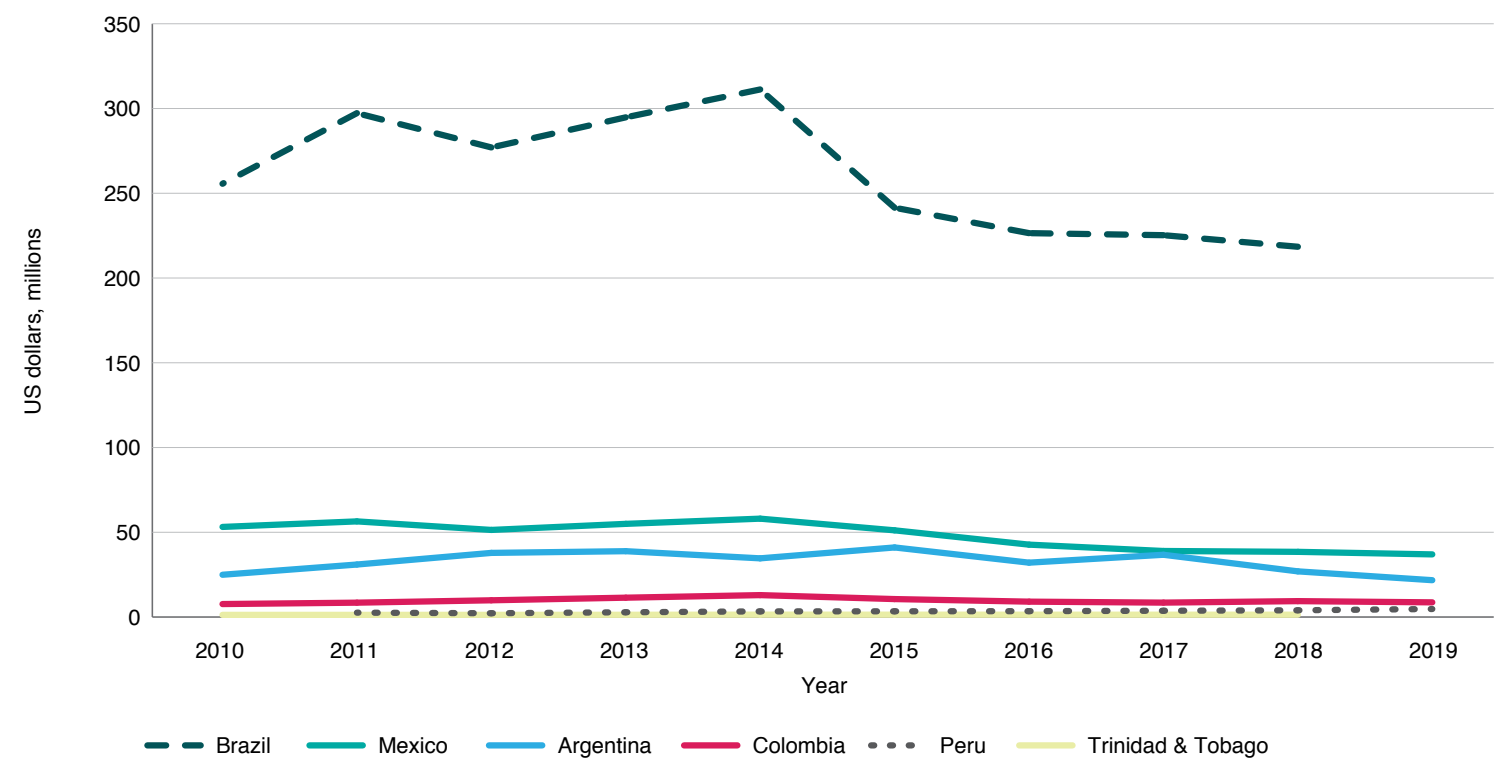

Source: rycit.org ${ }^{14}$

a Data shown for countries that reported to RICYT. Data not available for Barbados and Jamacia.

\section{Shifts in policies and impact}

Because of shifts in the political environment in some LACs, politics has played a role in government decision making, both favourable and unfavourable for health research funding. For instance, Brazil and Mexico moved away from well-established financing systems, which had secured funding for health research and continuity of ongoing research protocols. Brazil reduced funding for the entire Sc\&T sector, especially since the change in government in 2016. Mexico, by the end of 2011, had integrated 55 sectoral funds with national public entities and an international cooperation fund ${ }^{15}$ and the current administration elected in 2018, abolished all government funding for research from 2019 and has not financed health or any other research since.
Selected quotes below from interviewees shed light on the perceived impact of changes in the political environment in different LACs.

In Brazil, a researcher noted a significant decrease in funding:

We estimate a decrease of $70 \%$ of funding for health policy research since 2016 in Brazil, and it has also impacted the number of researchers wanting to conduct these types of studies. (HPSR researcher, Brazil)

However, more positively, Argentina moved from one-year grant funding for projects to multiyear project funding, improving the chances for more in-depth research projects to be funded. Both Argentina and Colombia in 2019 converted their Sc\&T councils into ministries, thus giving scientific research and innovation greater political visibility and priority. ${ }^{16,17}$ 
Certainly, the Ministry of Health defines the importance of doing health research by virtue of its institutional actions, such as creating a Directorate of Health Research... Now, how important it is, it is the most difficult thing to specify, because that clearly depends on who is in charge of the institution..." (Policy maker, Argentina)

In the Caribbean, $\mathrm{MoH}$ and universities play key funding roles in HPSR, together with international funding partners. The last reported health research agenda in the subregion was in 2011, produced by the then Caribbean Health Research Council. ${ }^{18}$ Currently, there are no set $\mathrm{MoH}$ policies specifically for HPSR; research financing is done without set priorities and is influenced by lobbyists or politics.

The politicians are the ones who decide what is funded. These decisions are driven by their political agendas, not necessarily by what is needed. (HPSR researcher, Trinidad and Tobago)

In the area of HPSR, we do not have the budgets or funding. It is seen as important, but the money simply is not there. COVID-19 is not making things any better. (HPSR researcher, Jamaica)

The main source [of HPSR funding] is governmental, I would guess $98 \%$ of the total, and there are also some resources that come from partnerships with international organisations, both governmental and non-profit. (HPSR researcher, Brazil)

Interview participants who were either HPSR or health/biomedical researchers recognised the value of HPSR. However, the extent of HPSR evidence used in decision making in the studied countries was unknown. Researchers in both groups agreed that HPSR funding was scarce and could be increased; they identified a need to strengthen national health research systems and overall financing throughout the $\mathrm{LAC}$ region.

That gap [exists]... between everything that is investigated and not used for management, because management does not know how to take advantage of it or is not directly aware of it. Or we have different methods... (Policy maker, Argentina)

...government health authorities [need] to understand the potential of research in health policies and systems, and that it should be seen as an auxiliary tool or mechanism for their decisionmaking. (HPSR researcher, Mexico)

\section{Discussion}

Even though HPSR is recognised in the LAC region for its value in decision making and policy design, it does not have the financial support it needs to flourish. The so-called progressive government in Mexico has not supported health or other scientific research development as expected ${ }^{19}$, stringent economic measures prompted by the deteriorating financial situation in some countries, even before the pandemic, had placed these countries in a fragile state.

Improvements in Argentina and Colombia, which introduced ministries for Sc\&T, were a positive step but the economic situation still restricts the availability of research financing and development. Argentina's foreign exchange policy (devaluation of its peso) has made it difficult for science to deliver. ${ }^{20}$ In Mexico, although budgetary cuts were seen as 'savings', these were used to subsidise government-defined investments, negatively affecting Sc\&T, health, education and other sectors. ${ }^{19,21}$ The impact will have to be measured in the near future, when some awarded funds come to end. ${ }^{22}$

Data about research and health research financing were not easy to access. In some instances, research teams had to request data through access-to-information regulations. Research funds reported by institutions in Brazil seemed to be reported in a duplicate manner by two institutions; in Peru information on funding was very limited and not easily accessible. There was little or no evidence in Peru of published reports or papers about the financing of research overall or health research and HPSR specifically.

An overall governmental open-data policy is needed in the $L A C$ region to facilitate access to data about research financing. Allowing civil society organisations to have access to funding and/or reporting about research funding and expenditure could be beneficial.

It has already been reported that available health research data are not up to date, and there are concerns about methodology and data accuracy in LAC region publications. Available data about overall expenditure on $\mathrm{R} \& \mathrm{D}$ are not disaggregated for the different areas being financed, for example biomedical, public health, and HPSR. ${ }^{23}$ Difficulties experienced by the country teams in accessing data reinforces our observation that the situation has not improved since similar research was conducted in 2014. ${ }^{23}$ The COVID-19 pandemic might have had an initial positive financial impact on health research in the field of biomedical research. However, there are negative economic forecasts that the $L A C$ region is facing an estimated regional Gross National Product (GNP) drop of $7.7 \%$ for 2020 with a slow recovery until $2023 .{ }^{24}$ The future of funding is uncertain. It is possible that research financing might have a lower priority in countries facing financial constraints in the near future because of a higher demand for funds for medical care and vaccines for COVID-19.

However, in the current COVID-19 pandemic, with the observed fragility of health systems, HPSR should have garnered increased interest from policy makers, funders and research teams. These stakeholders should focus on improving intersectoral communication; identify research priorities in HPSR related to health needs in every country, with consideration for the inequalities between 
and within countries. All WHO regional offices should devote a percentage of their budgets to HPSR capacity strengthening, and funding for implementation research, as a way to support health systems.

The impact of the COVID-19 pandemic on health systems and health policies must be assessed. HPSRgenerated evidence could guide the investment in health infrastructure to strengthen health systems and services that could improve health equity and access for populations affected by the pandemic.

Many factors influence decision making and policies around health research financing. Among these are ideological perspectives about the value of research and evidence, socioeconomic structures, political and legal systems, national economic conditions and administrative capacity, to mention just a few. Some of these factors are more relevant to the LAC region ${ }^{25}$, where most are uppermiddle or low-income countries. Important changes, such as sutainable budgets, progressive policies and research priorities are needed to improve the funding and relevance of HPSR and therefore encourage policy makers to value and use HPSR as evidence for day-today decision making. ${ }^{26}$

\section{Limitations}

This study has some limitations, including that there are just a small number of countries from the $L A C$ region included. Data on financing for health research and specific areas within, such as HPSR, are difficult to obtain and even more so when various bodies dealing with research funding may cause double counting of figures. The differences in criteria of research categories where HPSR may be included varies, thus making it difficult to obtain specific data. The pandemic made it especially difficult to establish direct contact with key stakeholders because $\mathrm{MoH}$ officials were consumed by the COVID-19 response.

\section{Conclusion}

This study demonstrates that countries in the $L A C$ region need to increase their budgets for HPSR to promote evidence-informed decisions for better health policies. LAC countries could consider partnerships with private institutions such as charitable foundations to diversify funding sources for the development of HPSR.

Scientific and technological activities require political support through concrete and realistic policies and strategies. In the case of HPSR research, for it to be competitive in gaining research funding, there should be greater focus on producing, disseminating, using and integrating research evidence to achieve a productive and social transformation of the health sector.

The global health agenda has been facilitating international initiatives such as the organisation of HPSR symposia. Now is the time to promote a wider debate within Latin America and the Caribbean to engage policy makers, HPSR and other health researchers, funding agencies and civil society to think strategically about the urgent need to support research to improve health policies and systems in the countries of the region.

There is a need to further study financing of health research and HPSR in particular, and even more so given that decisions during and after the pandemic will be needed to address structural changes in health systems. A standard categorisation of health research/ public health/social sciences would facilitate analysis and comparison of funding among countries and research bodies.

\section{Acknowledgements}

This work was supported by the Alliance for Health Policy and Systems Research, World Health Organization. The authors are themselves alone responsible for the views expressed in the article. This article does not represent the views, decisions, or policies of the Alliance for Health Policy and Systems Research.

\section{Peer review and provenance}

Externally peer reviewed, invited.

\section{Competing interests}

None declared.

\section{Author contributions}

FBP was responsible for the design, drafting, compilation of data and editing the manuscript. LSB was responsible for data gathering and editing the manuscript. BGG, EL, HMS, COD and UBP were responsible for data gathering, reviewing and editing the manuscript. DSB was responsible for data gathering and reviewing the manuscript. DTS was responsible for analytical support, data gathering, reviewing and editing the manuscript. $\mathrm{PV}$ was responsible for data gathering and reviewing the manuscript and MB was responsible for data gathering, analytical support and review of the manuscript.

\section{References}

1. World Health Organization. Report from the ministerial summit on health research: identify challenges, inform actions, correct inequities. Geneva: WHO; 2004 [cited 2021 May 1]. Available from: apps. who. int/iris/bitstream/handle/10665/43226/9241592951. pdf? sequence $=1 \&$ isAllowed $=y$

2. Lancet. The Mexico Statement: strengthening health systems. Lancet. 2004;364(9449):1911-1912. 
3. Pang T, Panisset U, Becerra-Posada F, Horton R, Frenk J. The spirit of Mexico: a decade on. Lancet. 2015;385(23):2028-29.

4. World Health Organization. World report on health policy and systems research. Geneva: WHO; 2017 [cited 2021 May 1]. Available from: apps.who.int/iris/bitstream/ handle/10665/255051/9789241512268-eng.pdf;jsessionid $=$ BE7A1A2871FBB3D383B231B5D6A7AFE7? sequence $=1$

5. Magan A, Plastow R, Haddad F. Impact of COVID-19 on research. Bone Joint Res. 2020;9(8):531-533.

6. Prudêncio M, Costa J. Research funding after COVID-19. Nat Microbiol. 2020;5:986.

7. Becerra-Posada F, dos Santos Boeira L, GarcíaGodoy MB, Lloyd E, Martínez-Sánchez HX, O'Donnell C, et al. Politics and political determinants of health policy and systems research funding in selected countries in Latin America and the Caribbean. Report prepared for the WHO Alliance of Health Policy and Systems Research; 2020 Nov. Available from authors.

8. Khor SK. Survey on political determinants and attitudes to HPSR funding. Geneva: Alliance for Health Policy and Systems; 2020 Aug 24. Available from authors.

9. The World Bank. World Bank country and lending groups, 2020 country classification. Washington, DC: The World Bank; 2020 [cited 2020 Nov 24] Available from: datahelpdesk.worldbank.org/knowledgebase/ topics/19280-country-classification

10. Scimago Journal \& Country Rank. Spain: SJR; 2021 [cited 2021 May 4]. Available from: www.scimagojr. com/countryrank. php?area=2700\&region=Latin\%20 America\&category $=2719$

11. Martínez-Martínez E, Zaragoza ML, Solano E, Figueroa B, Zúñiga P, Laclette JP. Health research funding in Mexico: the need for a long-term agenda. PLoS One 2012;7(12):e51195.

12. Government of Colombia. Creation of the sectoral funds in Colombia. Bogota: Government of Colombia; 2021 [cited 2021 Oct 11]. Available in Spanish from: https:// minciencias.gov.co/portafolio/fondo-fjc/que-es

13. World Bank. GDP growth (annual \%) - Latin America \& Caribbean. Washington, DC: The World Bank; 2021 [cited 2021 Oct 9]. Available from: data.worldbank.org/indicator/ NY.GDP.MKTP.KD.ZG?end=2020\&locations $=Z J \& s t a r t=20$ $10 \&$ view $=$ chart

14. RICYT. Ibero-American Network of Science and Technology. R\&D Expenditure in S\&T (PPP) 2010-2019. Spain: RICYT; 2021 [cited 2021 Oct 11]. Available from: app.ricyt.org/ui/v3/comparative.html?indicator=GAS_IMD_ PPC\&start_year=2010\&end_year=2019
15. González Block MA. Leadership, institution building and pay-back of health systems research in Mexico. Health Res Policy Syst. 2009;7(1):22.

16. Law of Ministries. Argentina creates Ministry of Science and Technology. Buenos Aires: Ministry of Justice and Human Rights; 2019 [cited 2021 Oct 25]. Available in Spanish from: servicios.infoleg.gob.ar/infoleglnternet/ anexos/330000-334999/333138/norma.htm

17. Columbian Government. Colombia will have for the first time in its history a Ministry of Science, Technology and Innovation. Bogota: Government of Colombia: 2021 [cited 2021 Oct 25]. Available in Spanish from: minciencias.gov. co/sala_de_prensa/colombia-tendra-por-primera-vez-ensu-historia-un-ministerio-ciencia-tecnologia-e

18. Caribbean Health Research Council. Health research agenda for the Caribbean. St Augustine: CHRC; 2011 [cited 2021 May 17]. Available from: www.carpha.org/ Portals/0/Documents/Health_Research_Agenda_for_the_ Caribbean.pdf

19. Ortega RP, Jaber IE. 'A brutal blow': a bill threatens dozens of trust funds that support Mexican science. Washington DC: Science: 2020 Oct 2 [cited 2021 Nov 2]. Available from: www.science.org/content/article/brutalblow-bill-threatens-dozens-trust-funds-support-mexicanscience

20. Aliaga J. Science and technology in Argentina 20152019. A view of the neoliberal adjustment. Science, Technology \& Politics. 2019:2(3);024.

21. Lazcano A. Quo vadis, Mexican Science? Science. 2019;365(6451):301.

22. Guglielmi, G. Mexican science suffers under debilitating budget cuts. Nature. 2019;572:294-5.

23. Becerra-Posada F, Minayo, M, Quental C, de Haan S. National research for health systems in Latin America and the Caribbean: moving towards the right direction? Health Res Policy Syst. 2014;12(13).

24. Barcina A, Cimoli M, Garcia-Buchaca R, Titelman D, Shaw S. Preliminary overview of the economies of Latin America and the Caribbean. Santiago: United Nations; 2021 [cited 2021 Oct 9]. Available from: repositorio.cepal. org/bitstream/handle/11362/46504/82/S2000989_en.pdf

25. Gilson L, Agyepong IA. National contexts. In: Gilson L, Orgill M, Cyrus Shroff Z (ed.) A health policy analysis reader: the politics of policy change in low-and middleincome countries. Geneva: World Health Organization, 2018 [cited 2021 May 1]. Available from: www.who.int/ alliance-hpsr/resources/publications/hpa-reader/en

26. Lavis J, Becerra-Posada F, Haines A, Osei E. Use of research to inform public policy making. Lancet. 2004;364:1615-21.

\section{Copyright: (c) (†)}

(C) 2021 Becerra-Posada et al. This article is licensed under a Creative Commons Attribution 3.0 IGO Licence, which allows others to redistribute, adapt and share this work for any purpose provided they attribute the work and indicate if changes were made. See: https:// creativecommons.org/licenses/by/3.0/igo/ 